\title{
ROLE OF DOPPLER SONOGRAPHY IN THE EVALUATION OF CHRONIC VENOUS INSUFFICIENCY IN LOWER LIMBS
}

\author{
Shravani Myadam1, Suman Chandra Aemjal'2, Vijaya Kumari M³
}

${ }_{1}^{1}$ Senior Resident, Department of Radiodiagnosis, Osmania Medical College.

2Professor, Department of Radiodiagnosis, Osmania Medical College.

${ }^{3}$ Associate Professor, Department of Radiodiagnosis, Osmania Medical College.

\begin{abstract}
BACKGROUND
BACKGROUND

The term chronic venous insufficiency refers to the venous valvular incompetence in the superficial, deep and/or perforating veins. Incompetence of the vein valves permits reversal of flow and promotes venous hypertension in the distal segments. This form of venous dysfunction may be the result of recanalisation of thrombosed venous segments, pathological dilatation of the vein or due to congenital absence of competent valves. The introduction of Doppler ultrasound technique has irrevocably altered the diagnosis and treatment of CVI. With colour Doppler, venous insufficiency can be localised to specific valve sites in the deep and superficial veins and incompetent perforators can similarly be identified and mapped prior to intervention.
\end{abstract}

\section{AIM}

To evaluate the spectrum of findings on Doppler ultrasound in patients who present with clinical symptoms and signs of chronic venous insufficiency.

\section{MATERIALS AND METHODS}

Prospective study of 50 patients with clinical suspicion of chronic venous insufficiency by Doppler imaging and ruling out Deep Vein Thrombosis (DVT), so that patients can be taken up for safe surgery.

\section{RESULTS}

Age of patients ranged from 19 to 80 years with mean age of 46 years. There was a male preponderance, and the left lower limb was the most common to be affected. Most common pathology in patients with chronic venous insufficiency was varicose veins. The most common site of reflux was perforator (most common level was below knee medial mid 1/3 rd).Among the patients with DVT, above knee deep veins were most commonly affected. Among the patients with CVI who underwent surgery, only 1 case did not show surgical correlation with the Doppler findings.

\section{CONCLUSION}

Doppler sonography is an accurate investigation in demonstrating the various spectrum of findings in a patient with CVI, important in planning the appropriate treatment and also has a high percentage correlation with operative findings.

\section{KEYWORDS}

Venous Insufficiency Lower Limb Doppler.

HOW TO CITE THIS ARTICLE: Myadam S, Aemjal SC, Kumari VM. Role of Doppler sonography in the evaluation of chronic venous insufficiency in lower limbs. J. Evolution Med. Dent. Sci. 2016;5(78):5806-5810, D0I: 10.14260/jemds/2016/1310

\section{INTRODUCTION}

The term chronic venous insufficiency refers to the venous valvular incompetence in the superficial, deep and/or perforating veins. Incompetence of the vein valves permits reversal of flow and promotes venous hypertension in the distal segments. This form of venous dysfunction may be the result of recanalisation of thrombosed venous segments, pathological dilatation of the vein or due to congenital absence of competent valves.

Venous insufficiency is associated with physical findings that are characteristic, yet these findings are non-specific with respect to cause.

Financial or Other, Competing Interest: None.

Submission 09-01-2016, Peer Review 21-08-2016,

Acceptance 23-08-2016, Published 28-09-2016.

Corresponding Author:

Dr. Shravani Myadam,

Plot No. 282,

Road No. 9, Vasavi Colony,

Hyderabad-500035.

E-mail: dr.sravi@gmail.com

DOI: 10.14260/jemds/2016/1310

(c) (i) $(9)$
They do not differentiate between obstruction and valvular incompetence, nor do they define the location or extent of valvular dysfunction. Varicose veins are the most common manifestation of CVI. Primary varicose veins result from venous dilatation without previous thrombosis. Secondary varicose veins are caused by valvular damage after Deep Vein Thrombosis (DVT) and recanalisation that gives rise to incompetent deep and perforating veins.

The introduction of Doppler ultrasound technique has irrevocably altered the diagnosis and treatment of CVI. This technique is non-invasive, repeatable, can be performed rapidly in the clinic at patient's bedside or even at home and the result is available immediately. It can be used in pregnant women, permits multiple views in various positions of the leg and the study is safe, painless and inexpensive. Venous system is evaluated for flow phasicity, compressibility and augmentation. It is useful as a screening modality in high-risk patients to ensure prompt and early treatment.

Duplex ultrasound complemented with colour flow imaging has been validated as a sensitive and specific modality for the identification of superficial and deep vein thrombosis. Valvular incompetence can be confirmed with spectral and 
colour Doppler, and unlike photoplethysmography and air plethysmography, venous insufficiency can be localised to specific valve sites in the deep and superficial veins. Incompetent perforators can similarly be identified and mapped prior to intervention.

\section{MATERIALS AND METHODS}

We prospectively evaluated 50 patients who were clinically suspected cases of venous disease of the lower limb, referred to the Department of Radiodiagnosis in Kamineni Institute of Medical Sciences. All patients underwent a detailed Doppler ultrasound study of the lower limb venous system. Doppler studies were performed on ESAOTE 50 MY LAB VISION, SIEMENS ACUSON X300 \& PHILIPS HD 15 ultrasound machines using high frequency (7-15 MHz) linear probes and low frequency (4-7 $\mathrm{MHz}$ ) curvilinear probes wherever required.

In all the patients a detailed study of the venous system of the affected lower limb was done with mapping of the incompetent sites wherever necessary after ruling out DVT.

In the patients who were operated, the level of incompetent sites on surgery was correlated with the Doppler findings.

\section{OBSERVATIONS AND RESULTS}

The present study included 50 patients with clinical suspicion of chronic venous insufficiency in the lower limb, who had undergone Doppler study of the affected lower limb.

A total of 20 patients were managed by surgery after proper assessment and exclusion of DVT.

The age group was wide varying from 19-80 years. Most common age group was $41-50$ years, (12 cases) accounting for $24 \%$ of the cases with the mean age of 46.62 (Table 1).

\begin{tabular}{|c|c|c|}
\hline Age Group (Yrs.) & No. of Study Subjects & (\%) \\
\hline 11 to 20 & 1 & 2 \\
\hline 21 to 30 & 11 & 22 \\
\hline 31 to 40 & 6 & 12 \\
\hline 41 to 50 & 12 & 24 \\
\hline 51 to 60 & 10 & 20 \\
\hline 61 to 70 & 2 & 16 \\
\hline 71 to 80 & $\mathbf{5 0}$ & 4 \\
\hline Total & $\mathbf{1 0 0}$ \\
\hline Table 1: Age Wise Distribution of Study Subjects in \\
Present Study (n=50) \\
\hline
\end{tabular}

The most common Doppler finding was chronic venous insufficiency accounting for $43(86 \%)$ of cases, followed by cellulitis (4 cases, 8\%) and Baker's cyst (3 cases, 6\%) (Fig. 1).

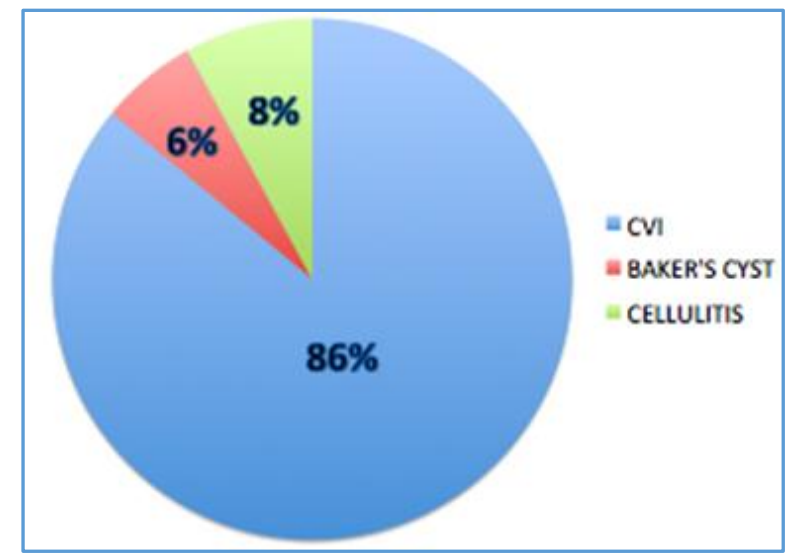

Fig. 1
The male-to-female ratio was $4.5: 1$ with a male preponderance (Table No. 2).

\begin{tabular}{|c|c|c|}
\hline Sex & No. of Study Subjects & Percentage (\%) \\
\hline Male & 41 & 82 \\
\hline Female & 9 & 18 \\
\hline Total & $\mathbf{5 0}$ & $\mathbf{1 0 0}$ \\
\hline \multicolumn{2}{|c|}{ Table 2: Sex Wise Distribution of Study Subjects in } \\
Present Study (n= 50)
\end{tabular}

The most common side of lower limb to be involved was left (23 cases, $46 \%$ ) as compared to right (16 cases, 32\%) or bilateral (11 cases, 22\%) (Fig. 2).

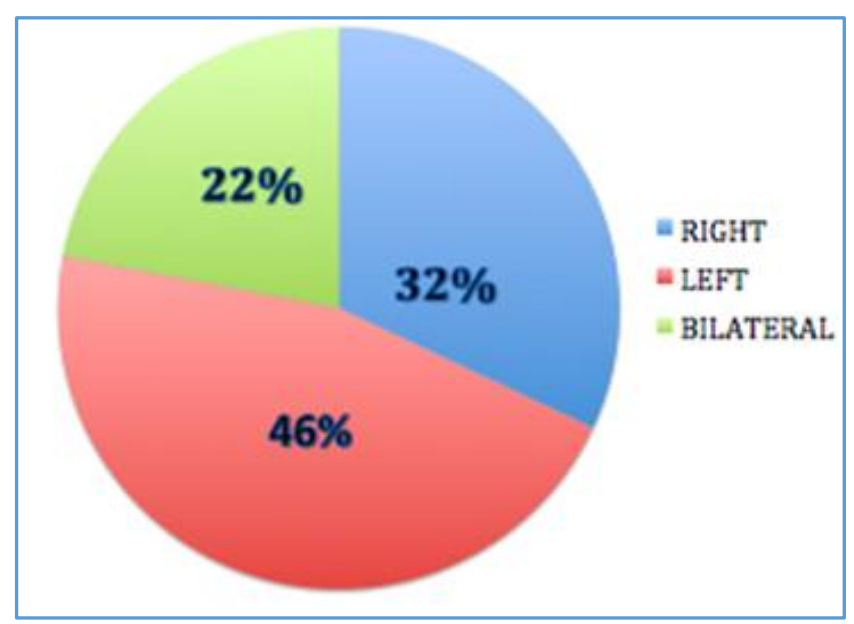

Fig. 2

The most common pathology in patients with chronic venous insufficiency ( 43 cases) was varicose veins (36 cases, 83.7\%) with the remaining 7 cases suffering from deep vein thrombosis (16.3\%) (Table No. 3).

\begin{tabular}{|c|c|c|}
\hline Pathology & $\begin{array}{c}\text { No. of Study } \\
\text { Subjects }\end{array}$ & (\%) \\
\hline Varicose Veins & 36 & 83.7 \\
\hline DVT & 7 & 16.3 \\
\hline Total & $\mathbf{4 3}$ & $\mathbf{1 0 0}$ \\
\hline Table 3: Distribution of Study Subjects with Chronic \\
Venous Insufficiency according to Pathology (n= 43) \\
\hline
\end{tabular}

Since many patients had bilateral involvement of varicosities, the " $n$ " was calculated as the no. of lower limbs involved which came up to 46 cases.

Most of the patients showed varicosities within the great saphenous vein (58.7\%) (Table No. 4).

\begin{tabular}{|c|c|c|}
\hline $\begin{array}{l}\text { Superficial Venous } \\
\text { System }\end{array}$ & $\begin{array}{l}\text { No. of Study } \\
\text { Subjects }\end{array}$ & $\begin{array}{l}\text { Percentage } \\
(\%)\end{array}$ \\
\hline $\begin{array}{l}\text { Great saphenous } \\
\text { vein }\end{array}$ & 27 & 58.7 \\
\hline $\begin{array}{l}\text { Short saphenous } \\
\text { vein }\end{array}$ & 1 & 2.1 \\
\hline Both (GSV and SSV) & 18 & 39.2 \\
\hline Total & 46 & 100 \\
\hline \multicolumn{3}{|c|}{$\begin{array}{c}\text { Table 4: Distribution of Study Subjects according to the } \\
\text { Superficial Venous System Involved }(n=46)^{*}\end{array}$} \\
\hline
\end{tabular}

The most common site of reflux was perforator (incompetence) with 27 cases (58.7\%) followed by mixed incompetence (both junctional and perforator) (16 cases, $34.9 \%$ ), sapheno-femoral incompetence in 2 cases (4.3\%) and a single case having only sapheno-popliteal junction incompetence (2.1\%) (Fig. 3). 


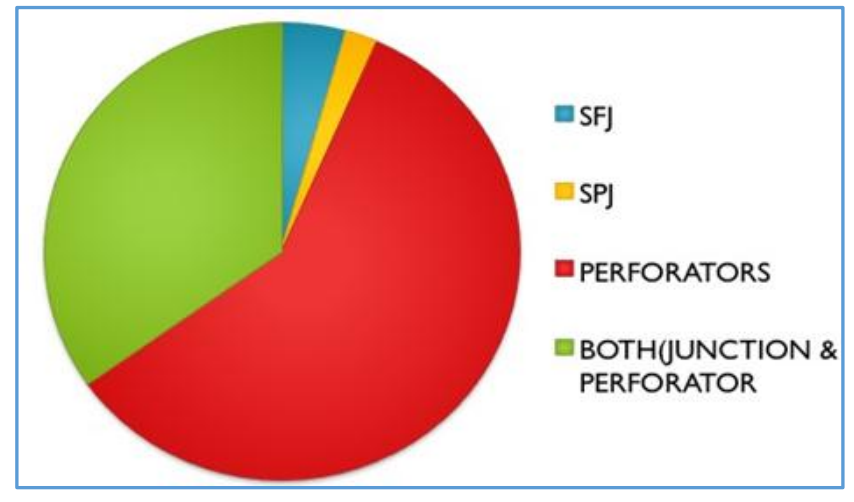

Fig. 3

Most of the patients had multiple level perforator incompetence, but the most common level was below knee medial mid $1 / 3^{\text {rd }}$ (32 cases, $69.5 \%$ ) and below knee medial lower $1 / 3^{\text {rd }}$ (31 cases, 67.4\%). The least incompetent perforator was anterior ( 1 case, $2.1 \%$ ) (Fig. 4 ).

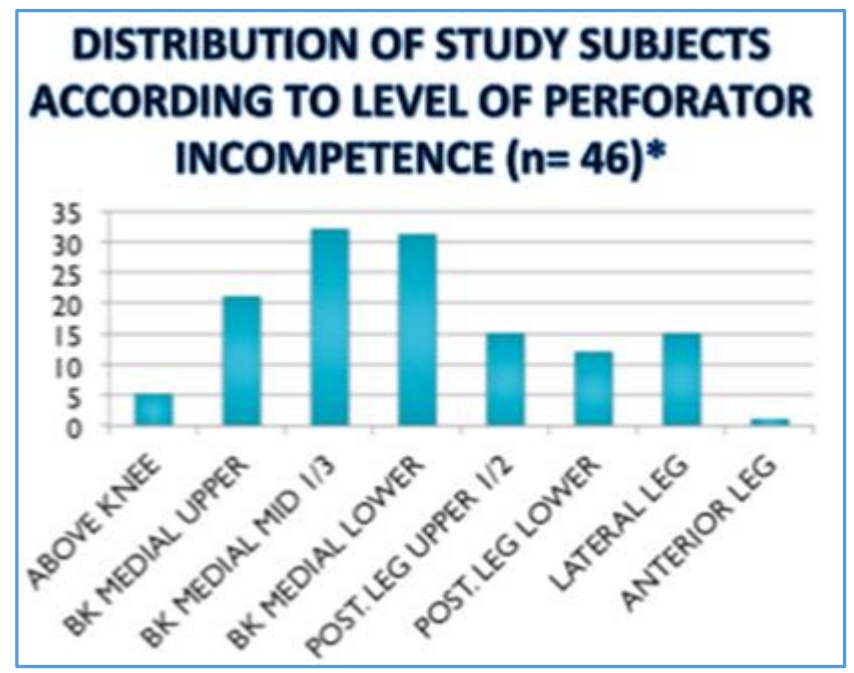

Fig. 4

Among 43 patients suffering from CVI, 8 of them had deep venous thrombosis with all of them having above knee thrombosis and none of them having below-knee thrombus (Table No. 5).

\begin{tabular}{|c|c|c|}
\hline $\begin{array}{l}\text { Segment } \\
\text { Involved* }\end{array}$ & $\begin{array}{l}\text { No. of Study } \\
\text { Subjects }\end{array}$ & (\%) \\
\hline EIV & - & \\
\hline $\mathrm{EIV}+\mathrm{CFV}$ & 1 & 14.26 \\
\hline EIV + THIGH (CFV+SFV) & 1 & 14.26 \\
\hline THIGH (CFV+SFV) & 1 & 14.26 \\
\hline $\begin{array}{c}\text { EIV + THIGH UPTO KNEE } \\
(\mathrm{CFV}+\mathrm{SFV}+\mathrm{PV}) \\
\end{array}$ & 2 & 28.57 \\
\hline $\begin{array}{l}\text { THIGH UPTO KNEE } \\
(\mathrm{CFV}+\mathrm{SFV}+\mathrm{PV})\end{array}$ & 2 & 28.57 \\
\hline BELOW KNEE (ATV+PTV) & - & \\
\hline \multicolumn{3}{|c|}{$\begin{array}{c}\text { Table 5: Anatomical Distribution of Thrombi in Study } \\
\text { Subjects with Deep Vein Thrombosis }(n=7)\end{array}$} \\
\hline
\end{tabular}

* (EIV - External Iliac Vein, CFV - Common Femoral Vein, SFV - Superficial Femoral Vein, PV - Popliteal Vein, ATV Anterior Tibial Vein, PTV - Posterior Tibial Vein).

Out of the 36 patients with varicose veins, 20 of them were operated and 19 (95\%) of them showed correlation of Doppler findings with the operative findings and the Doppler findings of only $1(5 \%)$ was not correlating with the operative findings (Fig. 5).

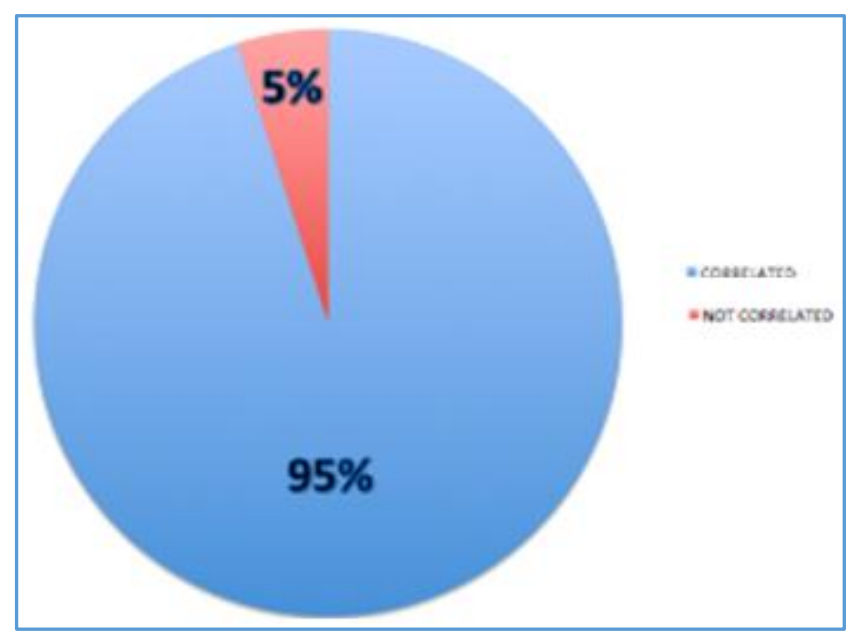

Fig. 5

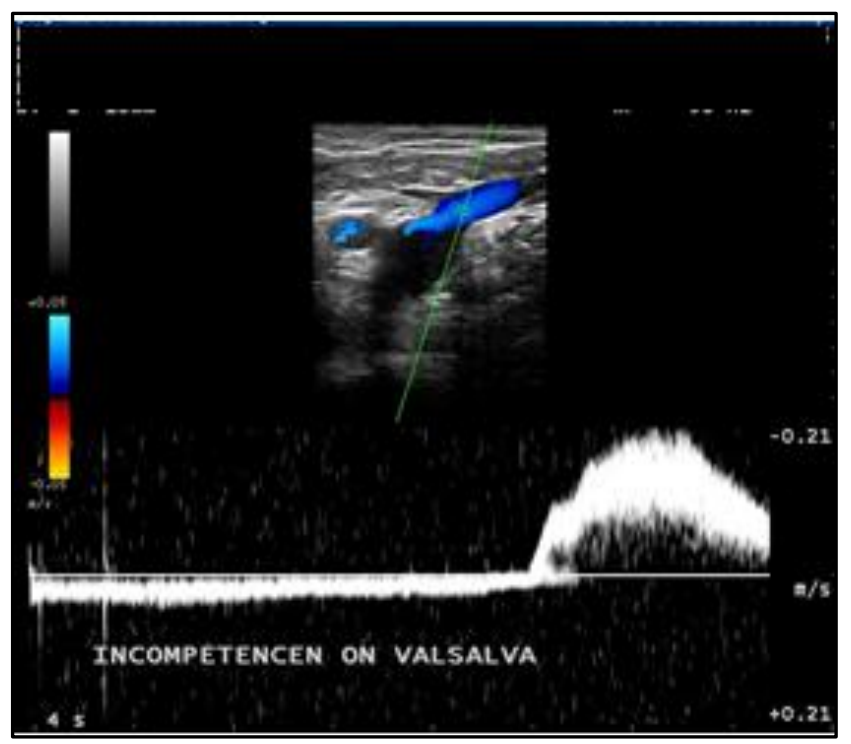

Fig. 6: Incompetence of the SFJ Demonstrated on Spectral Doppler Study

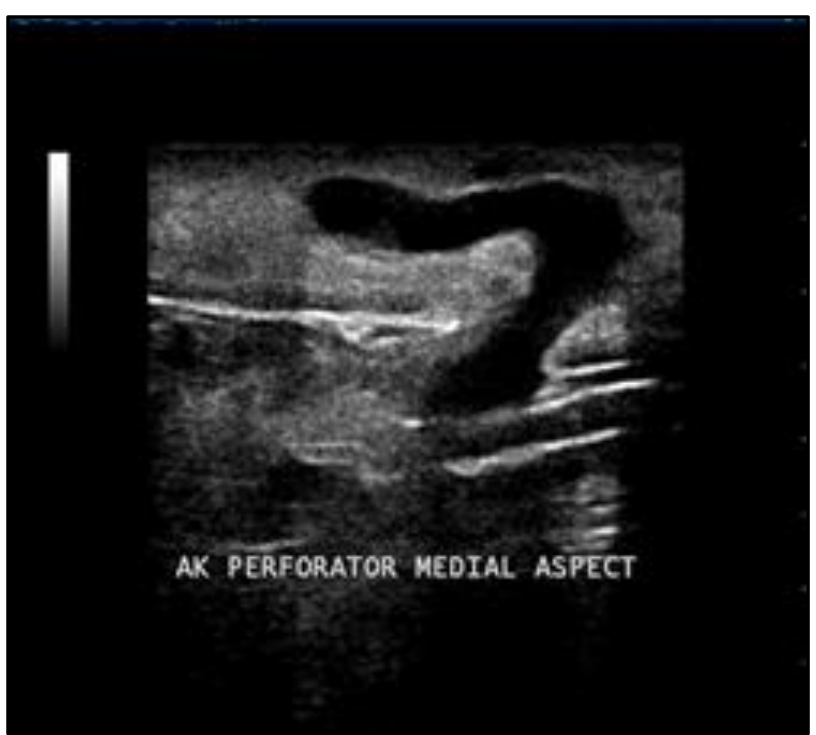

Fig. 7: The Incompetent Perforator in Medial Aspect Below the Knee 


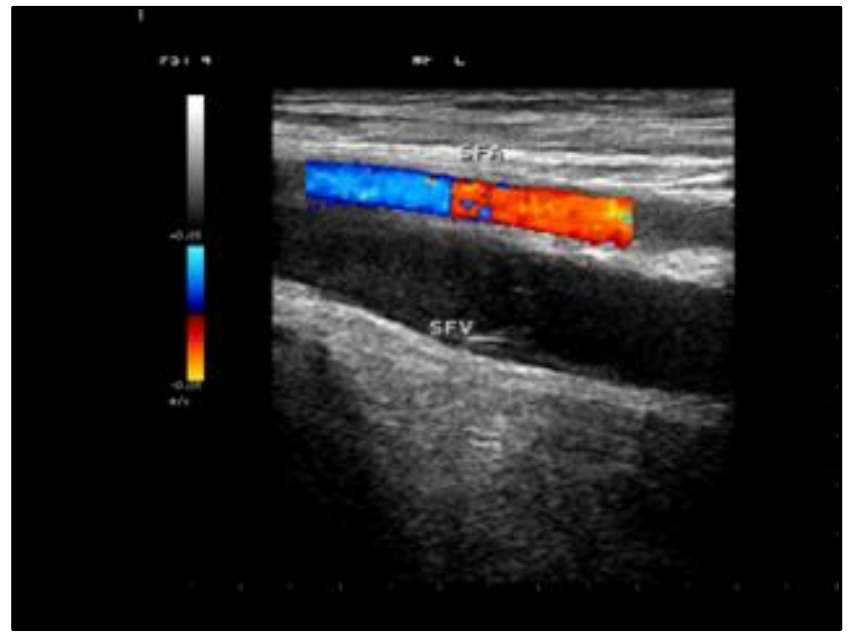

Fig. 8: Longitudinal Section of the Superficial Femoral Vessels shows Normal Colour Flow within the Artery, whereas the Vein shows No Colour Flow Within

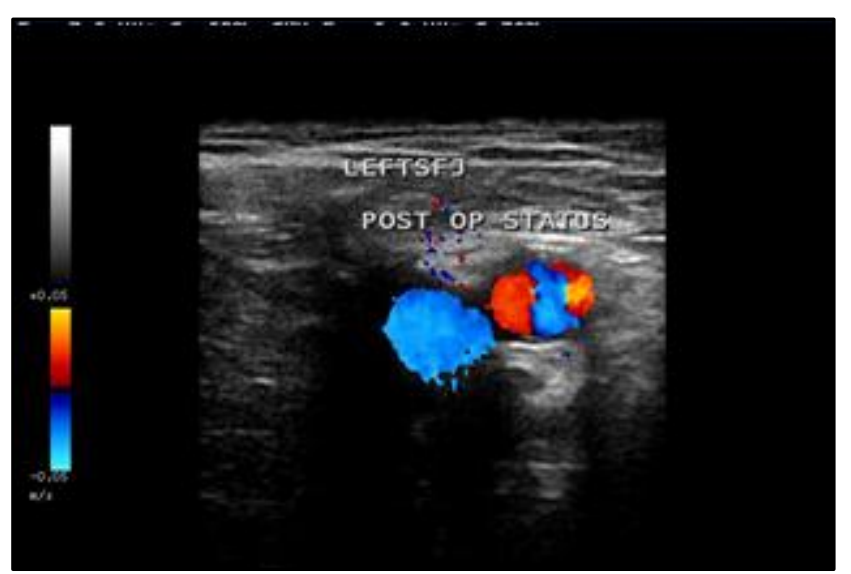

Fig. 9: Transverse Image of the Post-Operative Appearance of the Left SFJ

\section{DISCUSSION}

The study included 50 patients with clinical suspicion of chronic venous insufficiency, who had undergone duplex Doppler examination.

In the present study, $41(82 \%)$ were male and $9(18 \%)$ were female patients, which is in correlation with the study done by Aparna Irodi et al, who reported that most of the patients in the study group were males (55 patients) as compared to females (22 patients), and study by Pramod Mirji et al ${ }^{1}$ with only 8 female patients (25\%) and 24 (75\%) male patients.

However, varicose veins are classically described to be commoner in women, as proven by the Edinburgh vein Study (Evans et al). ${ }^{2}$

The lower incidence of chronic venous insufficiency in women in Indian population could be due to lesser number of Indian women seeking medical help.

In the present study, patients aged from 11 to 80 years were included in the study. The most common age group was found to be $41-50$ years with the mean age being 46.82 years. As compared to 20-40 yrs. being the most common age group in the study done by Pramod Mirji et al, ${ }^{1}$ which included patients aged from 20 yrs. to 65 yrs.

In the Edinburgh Vein Study (Evans, 1999), ${ }^{2}$ the prevalence of trunk varices rose from $11.5 \%$ in persons aged
18 to 24 years to $55.7 \%$ in the population between 55 to 64 years of age.

In the present study, there was a higher number of left sided limbs (23 patients, 46\%), affected than the right (16 patients, $32 \%$ ) or bilateral involvement (11 patients, $22 \%$ ) in correlation with the study done by Aparna Irodi et $\mathrm{al}^{3}$ who reported the most common side of involvement as left (59 limbs) when compared to right (41 limbs), and also with the study done by Pramod Mirji et $\mathrm{al}^{1}$ with the most common side of involvement being left $(15,46.87 \%)$ as compared to right $(14,43.75 \%)$

This was attributed to the crossing over of left common iliac vein by right common iliac artery giving rise to venous stasis. ${ }^{4}$

Also in a venographic study of the incidence of DVT, Stamatakis JD et al (1978) found that major thrombi occur more frequently in the left limb. 5

In the present study, out of the 46 limbs with varicose veins $27(58.7 \%)$ had varicosities of the GSV, while only 1 (2.1\%) patient had varicosities of the SSV and 18 (39.2\%) of them had varicosities of both GSV and SSV.

This is in correlation with the study done by Pramod Mirji et al (2011) ${ }^{1}$ among the 32 patients examined, 29 (90.63\%) had varicosities of the GSV, while only 1 (3.13) patient had SSV varicosities and $2(6.25 \%)$ of them had varicosities of both GSV and SSV.

Incompetent perforators were seen in most of the cases in the present study (43 limbs, 93.6\%). Isolated perforator incompetence was noted in 27 limbs (58.7\%). Most of the perforators were found in the medial aspect of the leg, with below knee medial mid-1/3rd level of perforators being the most common (32 perforators, 69.5\%). Most of the patients had more than 1 incompetent perforator, 2-3 being most common.

This is in correlation with the study done by Aparna Irodi et al (2011), ${ }^{3}$ who found perforator incompetence in $96 \%$ of their cases with isolated perforator incompetence in $4 \%$ of the cases and 77 below knee medial mid- $1 / 3^{\text {rd }}$ level of perforator incompetence.

In the present study DVT was seen in 7 of the cases. All of the cases were acute and showed thrombus within the deep veins of the proximal segment. (Above knee veins) with involvement of external iliac, femoral and popliteal veins in 2 patients $(28.57 \%)$ and involvement of only femoral and popliteal segments in 2 patients (28.57\%) being the most common.

This roughly correlates with the study by Hill SL et al (1997), ${ }^{6}$ who found $49 \%$ thrombi in the thigh or popliteal region without calf involvement. The study reported involvement of iliofemoral segment in $16 \%$, CFV in $13 \%$, SFV in $19 \%$, PV in $18 \%$, calf veins in $24 \%$ and superficial veins in $11 \%$.

In the present study of 50 patients, 43 of them had CVI on Doppler examination. Among which 7 of them were not fit for surgery due to the presence of DVT.

In the remaining 36 patients with varicose veins 20 of them were operated, after venous mapping done by Doppler examination of the affected lower limb. Only 1 case among the 20 patients showed recurrence of varicosities in the immediate post-operative phase due to presence of the vein of Giacomini \{When the SPJ drains via the thigh extension (TE SSV) and Posterior Thigh Circumflex Vein (PTCV) into the GSV, the vein is called the vein of Giacomini\}, ${ }^{7}$ which was not identified in the routine venous mapping before the surgery. 
Thus the sensitivity of duplex Doppler examination and venous mapping prior to surgery was $95 \%$, which is in correlation with the study done by Peter M Dixon in 1996. Peter M Dixon reported a sensitivity of $98 \%$ in his study. ${ }^{8}$

\section{CONCLUSION}

The present study of Doppler examination of lower limb for chronic venous insufficiency, 50 patients were examined in Kamineni Institute of Medical Sciences and the spectrum of findings recorded, which are as follows:

1. Most common age group was $41-50$ years (12 patients, 24\%).

2. Male preponderance was observed ( 41 patients, $82 \%$ ).

3. Left (23 patients, $46 \%$ ) lower limb being more affected than right (16 patients, $32 \%$ ) or bilateral (11 patients, $22 \%)$.

4. Among the 50 patients examined $43(86 \%)$ of them had chronic venous insufficiency, 4 (8\%) had cellulitis and 3 (6\%) had Baker's cyst.

5. Of the 43 patients with chronic venous insufficiency, 7 $(16.3 \%)$ patients had acute DVT; the remaining 36 $(83.7 \%)$ patients had varicose veins.

6. Among the 46 limbs with varicose veins, 27 (58.7\%) cases had GSV varicosities, 1 (2.1\%) had SSV varicosities and $18(39.2 \%)$ had involvement of both GSV and SSV.

7. Perforator incompetence (58.7\%) was the most common cause for varicosities.

8. Below knee medial mid-1/3rd perforators (69.5\%) were found to be the most common incompetent perforators.

9. All the 7 patients with deep vein thrombosis showed involvement of the proximal segment veins.

10. Among the 36 patients with varicose veins, 20 of them underwent surgery after preoperative mapping of the venous system; 19 (95\%) of the patients were in agreement with the surgical findings.
Doppler sonography is an accurate investigation in demonstrating the various spectrum of findings in a patient with CVI, important in planning the appropriate treatment and also has a high percentage correlation with operative findings.

\section{REFERENCES}

1. Mirji P, Emmi S, Joshi C. Study of clinical features and management of varicose veins of lower limb. Journal of Clinical and Diagnostic Research 2011;5(7):1416-20.

2. Evans CJ, Fowkes FG, Ruckley CV, et al. Prevalence of varicose veins and chronic venous insufficiency in men and women in the general population: edinburgh vein study. J Epidemiol Community Health 1999;53(3):14953.

3. Irodi A, Keshava SN, Agarwal S, et al. Ultrasound doppler evaluation of the pattern of involvement of varicose veins in indian patients. Indian J Surg 2011;73(2):12530.

4. Rutherford RB. Vascular surgery. $4^{\text {th }}$ edn. Philadelphia: WB Saunders Company 1995:67-9.

5. Stamatakis JD, Kakkar VV, Lawrence D, et al. The origin of thrombi in the deep veins of the lower limb: a venographic study. Br J Surg 1978;65(7):449-51.

6. Hill SL, Holtzman GI, Martin D, et al. The origin of lower extremity deep vein thrombi in acute venous thrombosis. Am J Surg 1997;173(6):485-90.

7. Oğuzkurt L. Ultrasonographic anatomy of the lower extremity superficial veins. Diagn Interv Radiol 2012;18(4):423-30.

8. Dixon PM. Duplex ultrasound in the pre-operative assessment of varicose veins. Australasian Radiology 1996;40(4):416-21. 